\title{
Mujeres víctimas de violencia sexual, su derecho a la reparación en el proceso de transición de la Ley de Justicia y Paz en la Inspección El Placer, departamento de Putumayo, 2010-2015
}

\author{
Female Victims of Sexual Violence, their Right to Reparation \\ in the Transition Process of the Justice and Peace Act at the \\ El Placer Police Station, Department of Putumayo, 2010-2015 \\ Lady Andrea Calderón Robledo ${ }^{1} \bowtie$ \\ ${ }^{1}$ Aspirante a magíster en Derechos Humanos y Derecho Internacional de los Conflictos Armados \\ de la Escuela Superior de Guerra. Especialista en Derechos Humanos de la Escuela Superior de \\ Administración Pública. Especialista en Derecho Sancionatorio de la Universidad Militar Nueva Granada. \\ Abogada egresada de la Universidad de la Amazonia en el 2010.
}

Correo electrónico: andrecal012@hotmail.com

Recibido: 30 de octubre del 2017 Aprobado: 8 de enero del $2018 \quad$ Disponible en línea: 1 de abril del 2018

Cómo citar este artículo: Lady Andrea Calderón-Robledo. Mujeres víctimas de violencia sexual, su derecho a la reparación en el proceso de transición de la Ley de Justicia y Paz en la Inspección El Placer, departamento de Putumayo, 2010-2015. DIXI 27. Abril 2018. doi: https://doi.org/10.16925/di.v20i27.2391

\section{Resumen}

Objetivo: el presente artículo muestra cómo las mujeres víctimas de violencia sexual en el marco del conflicto armado continúan a la espera de ser reparadas, pese a lo dispuesto por la normativa colombiana, que desde la Ley de Justicia y Paz ha promovido un esquema en materia de reparación que sigue siendo frágil, debilitando la respuesta del Estado colombiano en cuanto a la protección de los derechos humanos.

Metodología: para tal fin, la investigación se llevó a cabo en la Inspección El Placer, jurisdicción del municipio del Valle del Guamuez, en el departamento de Putumayo, a través de un método mixto -cualitativo-cuantitativo- acompañado de un estudio de caso, con una muestra focalizada que permitió encuestar a víctimas y a funcionarios de la inspección.

Resultados: se estableció que las víctimas en el proceso penal tendrían tres garantías: el derecho a la verdad, el derecho a la justicia y el derecho a que no haya impunidad.

Conclusiones: se concluyó que en la Inspección El Placer las mujeres que han sido víctimas de violencia sexual en su mayoría no han sido reparadas, que la transición entre la Ley de Justicia y Paz y la justicia transicional no ha reflejado sus frutos en la materia y que continúa la invisibilización de las víctimas.

Palabras clave: conflicto armado, derechos humanos, reparación, víctimas, violencia sexual.

$1 \quad$ El presente artículo de investigación es presentado como opción de grado para optar al título de magíster en Derechos Humanos y Derecho Internacional de los Conflictos Armados de la Escuela Superior de Guerra, y es producto del proyecto de investigación "Derecho operacional como instrumento eficaz para la protección de la población civil y la seguridad jurídica institucional como individual en Colombia”, vinculado al Grupo de Investigación Derechos Humanos, Derecho Internacional de los Conflictos Armados y Justicia, inscrito en Colciencias. 


\title{
Female Victims of Sexual Violence, their Right to Reparation in the Transition Process of the Justice and Peace Act at the El Placer Police Station, Department of Putumayo, 2010-2015
}

\begin{abstract}
Purpose: This article shows how female victims of sexual violence in the context of the armed conflict are still waiting to be repaired, despite the provisions in the Colombian regulations, which, since the Justice and Peace Act, have promoted a reparation scheme that remains fragile, weakening the response of the Colombian State regarding the protection of human rights.

Methods: For this purpose, the research was conducted at the El Placer Police Station, jurisdiction of the municipality of Valle del Guamuez, in the department of Putumayo, through a mixed-qualitative-quantitative - method along with a type of case study, using a focused sample that allowed surveying victims and officials at the Police Station.

Results: It was established that the victims in the criminal process would have three guarantees: the right to the truth, the right to justice, and the right to no impunity.

Conclusions: It was concluded that, at the El Placer Police Station, women who have been victims of sexual violence have not been repaired, that the transition between the Justice and Peace Act and transitional justice has not produced results in the matter, and that the invisibility of victims continues.
\end{abstract}

Keywords: armed conflict, human rights, reparation, victims, sexual violence.

\section{Mulheres vítimas de violência sexual, seu direito à reparação no processo de transição da Lei de Justiça e Paz na Inspeção El Placer, departamento de Putumayo, 2010-2015}

\begin{abstract}
Resumo
Objetivo: este artigo expõe como as mulheres vítimas de violência sexual no contexto do conflito armado ainda aguardam a reparação apesar das disposiç̧̃es da lei colombiana que, desde a Lei de Justiça e Paz, promoveu um esquema de reparação que permanece frágil e enfraquece a resposta do Estado colombiano em relação à proteção dos direitos humanos.

Metodologia: para este fim, realizou-se a investigação na Inspeção El Placer, jurisdição do município de Valle del Guamuez, no departamento de Putumayo, através de um método misto (qualitativo-quantitativo) acompanhado por um tipo de estudo de caso, com uma amostra focada que permitiu fazer uma sondagem às vítimas e aos funcionários da Inspeção.

Resultados: estabeleceu-se que as vítimas teriam três garantias no processo penal: 0 direito à verdade, 0 direito à justiça e 0 direito de não ter impunidade.

Conclusões: concluiu-se que na Inspecção El Placer, a maioria das mulheres que foram vítimas de violência sexual não foram reparadas, que a transição entre a Lei de Justiça e Paz e a justiça de transição não deu resultados e que as vítimas continuam a ser invisíveis.
\end{abstract}

Palavras-chave: conflito armado, direitos humanos, reparação, vítimas, violência sexual. 


\section{INTRODUCCIÓN}

Se llama El Placer, pero de 1999 al 2006 fue el infierno. Durante esos años, los pobladores de esta inspección de La Hormiga (Putumayo), a orillas del río Guamuez, fueron víctimas de una crueldad inimaginable. Todo comenzó el 7 de noviembre de 1999 cuando los paramilitares llegaron al pueblo. En ese momento, El Placer era controlado por el Frente 48 de las Fuerzas Armadas Revolucionarias de Colombia (FARC), aunque ya las Autodefensas Unidas de Colombia (AUC) se movían por la región. Habían pasado por el corregimiento El Tigre, zona rural de La Hormiga, donde el 9 de enero de ese mismo año asesinaron a veintiséis personas, según reportes oficiales ${ }^{2}$.

Cuando el padre Nelson Cruz llegó a El Placer, en 1996, encontró una casa cural en obra negra y una ínfima capilla perdida en un potrero. Encontró también un pueblo en pleno apogeo de la coca, con más discotecas que tiendas y una población con poco tiempo para las cuestiones del espíritu, mucho menos para ir a misa ${ }^{3}$.

El Placer, una de las siete inspecciones de Policía que conforman el municipio Valle del Guamuez, ha sido y sigue siendo uno de los puntos neurálgicos del conflicto en Putumayo. Ese territorio fronterizo y de colonización nariñense ha sido epicentro del narcotráfico y escenario de distintos y sucesivos órdenes armados $^{4}$.

La guerra construyó formas específicas de ser mujer y a partir de un ejercicio de diferenciación entre mujeres decentes e indecentes, estableció fronteras entre ellas que quebraron el tejido social: "[...] este informe reconstruye los repertorios de violencia, regulación y control desplegados por el Frente 48 de las FARC y, posteriormente, por el Bloque Sur Putumayo de las Auc para devenir autoridad y establecer su dominio en El Placer"

\footnotetext{
2 Véase Sebastián Jiménez Herrera. Cuando El Placer fuE UN INFIERNo. El Espectador. 28 de septiembre de 2012. Disponible en http://www.elespectador.com/noticias/judicial/cuando-elplacer-fue-un-infierno-articulo-378231

Véase Centro Nacional de Memoria Histórica ( $\mathrm{CNMH)}$ Galería El Placer Putumayo. Fotografías de Jesús Abad Colorado y María Luisa Moreno. Marzo 1 de 2014. Disponible en http://www.centrodememoriahistorica.gov.co/de/informes/informes-2018/el-placer-putumayo

4 Véase María Clemencia Ramírez. El Placer: Mujeres, coca y guerra en el Bajo Putumayo. Centro Nacional de Memoria Histórica. (2012). Pág. 17.

5 Id. Pág. 19.
}

Diversos han sido los estudios elaborados para tratar de comprender los orígenes y las particularidades del conflicto armado en Colombia; así mismo, cada autor desde su perspectiva de estudio indica un inicio a veces diferente. Algunos coinciden en que el conflicto colombiano tiene sus raíces en los enfrentamientos entre los partidos Liberal y Conservador, defendiendo dos puntos que llegan a ser divergentes: una mirada religiosa y radicalista y una visión liberal del mundo ${ }^{6}$. En últimas, todo apunta a un conflicto por el poder y la tenencia de la tierra, disputa acontecida entre grupos de carácter insurgente, el Estado y la contrainsurgencia, y para muchos investigadores estas dos últimas llegan a ser el mismo lado de la moneda ${ }^{7}$.

Más allá de las causas o las razones que siguen manteniendo los actores armados, hay un grupo de personas que han sufrido las vicisitudes de una guerra en la cual no tienen un papel incidente, sino que están expuestas a todas las afectaciones de los enfrentamientos armados, convirtiéndose en blanco fácil y vulnerable. Este grupo son las víctimas del conflicto armado, que desde la Ley 1448 de 2011, en el artículo 3 , reciben la siguiente definición:

[...] aquellas personas que individual o colectivamente hayan sufrido un daño por hechos ocurridos a partir del 1 de enero de 1985, como consecuencia de infracciones al Derecho Internacional Humanitario o de violaciones graves y manifiestas a las normas internacionales de Derechos Humanos, ocurridas con ocasión del conflicto armado interno [...]

En lo establecido por la Unidad para las Víctimas y el Centro Nacional de Memoria Histórica (CNMH), existen trece tipologías de victimización en el marco del conflicto armado; entre esas modalidades, la que es de interés para este proyecto investigativo es la novena: delitos contra la libertad y la integridad sexual $^{8}$. Como componentes de este crimen, aparecen: la violación sexual, el matrimonio o cohabitación forzada, la esclavitud sexual, el aborto, la amenaza de violencia sexual, el chantaje sexual, etc.

En este orden de ideas, "la violencia sexual contra la mujer es una práctica habitual, extendida, sistemática e invisible en el contexto del conflicto

\footnotetext{
6 Véase Eduardo Pizarro Leongómez. UNA LECTURA MúltiPle Y PluRalista de la historia. Comisión Histórica del Conflicto y sus Víctimas. (2015). Pág. 9.

7 Id. Pág. 21.

8 Id. Pág. 74
} 
armado colombiano, así como lo son la explotación y el abuso sexual por parte de todos los grupos armados ilegales enfrentados"'; práctica que "retrata una realidad silenciosa que se vive a diario en Colombia, la violencia de género como un arma de guerra"10. Se tiene, entonces, que la mujer en el marco del conflicto se ha convertido en botín de guerra. En el informe ¡Basta ya!, el CNMH señala que "la violencia sexual es el crimen más invisible cometido durante el conflicto armado. Las 1.754 víctimas reportadas por el Registro Único de Víctimas expresan que este delito no ha sido un crimen aislado, como pretenden justificarlo insistentemente los actores armados"11.

Son evidentes las violaciones a los derechos humanos y las graves infracciones a las normas del Derecho Internacional Humanitario (DIH), partiendo de la base de que es el propio Estado colombiano el que más ha infringido los derechos de las víctimas de violencia sexual.

En esta medida, los derechos humanos constituyen el fundamento del Estado colombiano y del pacto social que representa la Constitución Política de 1991, y por lo tanto, deben respetarse en cualquier actuación social, sea esta llevada a cabo por el Estado o por los particulares, en pro de la dignidad humana. Dicha situación no es ajena a la vivida por las mujeres de la Inspección El Placer, jurisdicción del municipio Valle del Guamuez, Putumayo, que son el objeto de estudio de la presente investigación, realizada en el marco de la Ley de Justicia y Paz en el periodo 2010-2015, cuya pregunta principal fue: ¿cuál ha sido el impacto de la política en materia de reparación a las víctimas de violencia sexual en el marco del proceso de transición derivado de la Ley de Justicia y Paz en la Inspección El Placer-Putumayo, 2010-2015?

La pregunta se abordó partiendo del hecho de que la dignidad humana constituye un mandato constitucional, un deber positivo o un principio de acción, según el cual todas las autoridades del Estado, sin excepción, en la medida de sus posibilidades físicas y materiales, deben realizar todas las conductas relacionadas con sus funciones constitucionales y

\footnotetext{
9 Véase Corte Constitucional de Colombia. Auto 092/08. (M.P. Manuel José Cepeda; abril 14 de 2008).

10 Véase Redacción El Heraldo. Violencia sexual, EL CRIMEN SILENCIOSO DEL CONFLicto ARMAdo. El Heraldo. 6 de abril de 2015. Disponible en https://www.elheraldo.co/politica/violencia-sexual-el-crimen-silencioso-del-conflicto-armado-190276

11 Véase Centro Nacional de Memoria Histórica (CNMH). iBASTA ya! Colombia: Memorias de GUERRA Y DignidAD. CNMH. (2013). Pág. 31.
}

legales con el propósito de lograr las condiciones para el desarrollo efectivo de los ámbitos de protección de la dignidad humana de las mujeres víctimas de la violencia sexual en la Inspección El Placer.

Se ha escogido la Inspección El Placer debido a los daños orientados a las mujeres, que han vivido situaciones de violencia sexual a nivel individual y colectivo, causadas en especial por el Bloque Sur Putumayo de las AUC, que estigmatizaron a los pueblos del territorio por ser aparentemente "guerrilleros"; los paramilitares empleaban "el terror" como mecanismo para suprimir y eliminar a toda persona de la que tuvieran la sospecha de ser guerrillero. La mujer, para los grupos paramilitares, se convirtió en cuerpo del deseo, la tortura y el control hacia la población.

Se tiene entonces que en el marco de la Ley de Justicia y Paz-Ley 975 de 2005 se logró "develar parcialmente una verdad que hubiera sido imposible de obtener por otros medios, así como ciertas vinculaciones con elementos de la esfera política, lo que constituye un importante punto de partida"12. Al respecto, el Estado ha indicado que los progresos alcanzados con la implementación de la Ley de Justicia y Paz se han centrado en los componentes de verdad, justicia y reparación: "En materia de reparación, Colombia sostiene que el marco normativo desarrollado para los procesos de Justicia y Paz permite concentrarse en esclarecer los patrones de macrocriminalidad y las afectaciones causadas a las víctimas"13.

Partiendo del hecho de que la Ley de Justicia y Paz ha sido fundamental para este proceso, se encontró un espacio interesante para analizar la responsabilidad de esta ley en materia de reparación de las mujeres víctimas de violencia sexual en la Inspección El Placer, uno de los territorios de mayor incidencia de grupos alzados en armas. Al ser fronterizo, es "propicio para el narcotráfico, sobre todo de coca, la cual empezó cerca de la década de los setenta, y con ella llegaron guerrilla, paramilitares y otros grupos delincuenciales"14. Escenario que ha sido favorable para perpetrar toda clase de ataques a la población civil, siendo la violencia sexual contra la mujer uno de los más frecuentes.

De esta forma, el objetivo general de la investigación fue: analizar cuál ha sido el impacto de la política

12 Véase Comisión Interamericana de Derechos Humanos (CIDH). Verdad, JUSticia y Reparación. Cidh. (2013). Pág. 136. 13 Id.

14 María Clemencia Ramírez, supra, nota 4, Pág. 17. 
en materia de reparación a las víctimas de violencia sexual en el marco del proceso de transición derivado de la Ley de Justicia y Paz, en la Inspección El PlacerPutumayo en el periodo comprendido entre los años 2010 y 2015. Lo expuesto parte del hecho de que en materia de política, seguridad y defensa la importancia del tema radica en la necesidad de recuperar el orden, la seguridad y la credibilidad en el DIH, en pro de la reparación a las mujeres víctimas de abuso sexual en la Inspección El Placer en el periodo de estudio.

Para tal fin, la investigación se desarrolló a partir de un diseño metodológico mixto, centrado en el método cualitativo -cuyo objetivo es la descripción de las cualidades de un fenómeno que abarca parte de la realidad de un objeto de estudio- y acompañado de un estudio de caso, que "tiene como particularidad básica abordar de forma intensiva una unidad, esta puede orientarse a una persona, una familia, un grupo, una organización o una institución"15. Puede ser algo simple o complejo, pero siempre una unidad. Así, el estudio de caso como un enfoque se sitúa en un paradigma: "[...] lo que significa una postura general frente a la existencia misma y la forma de ubicarse con respecto al conocimiento. Los estudios de caso pueden ser abordados como parte integral de un enfoque como el cualitativo"16. Para la investigación se escogió el estudio de caso "típico", que hace referencia a una o varias personas que representan a una comunidad, con un aspecto común o cierta homogeneidad o coherencia en las respuestas, como las que se lograron con las mujeres víctimas de violencia sexual en la Inspección El Placer.

A su vez, se tomó una muestra focalizada -es decir que "poseen un mismo perfil o característica, comparten rasgos similares y cuyo fin es centrarse en el tema a investigar o resaltar situaciones, procesos o episodios en un grupo social"17-, que para el caso fue de siete víctimas de violencia sexual en la Inspección El Placer. El trabajo de campo fue realizado a través

15 Véase Robert E. Stake. Case studies. Ed. Yvonne S. Lincoln y Norman K. Denzin. Handbook of Qualitative Research. Sage. (1994). Pág. 239.

16 Véase Manuel Muñiz. Estudio de CAso en LA investigaCión CUalitativa. Disponible en http://www.psico.edu.uy/sites/ default/files/cursos/1_estudios-de-caso-en-la-investigacion-cualitativa.pdf. Pág. 2.

17 Véase Roberto Hernández Sampieri, Carlos Fernández Collado y Pilar Baptista Lucio. Metodología de LA investigaCIón. McGraw-Hill. (2010). Pág. 398. de una lista de chequeo que permitió determinar los avances o retrocesos en materia de reparación, y a través de la aplicación de una entrevista semiestructurada a tres funcionarios de la Inspección relacionados con el tema de la reparación de víctimas.

\section{Análisis de la Ley de Justicia y Paz y la violencia sexual contra la mujer}

La Ley de Justicia y Paz del 2005 nació a raíz del conflicto armado colombiano, el cual se caracterizó por sus diversas formas de ejercer el poder para causar intimidación y rendición. Uno de estos mecanismos, y bastante empleado por todos los grupos paramilitares, fue el uso de la violencia sexual como arma de guerra, cuyo objetivo principal era lograr fines militares generando terror usando a las mujeres.

Tras la entrega de armas por los grupos paramilitares, muchas mujeres dieron a conocer innumerables historias de abusos y violencias: "De acuerdo con la Unidad de Justicia y Paz, en el 66 por ciento del territorio nacional, es decir, en 21 de los 32 departamentos, los integrantes de grupos paramilitares cometieron delitos sexuales"18. Las prácticas de este tipo que se llegaron a ejecutar fueron: embarazos en menores de edad, esclavitud y servidumbre, entre muchas otras.

La Corporación Sisma Mujer ${ }^{19}$, en su investigación sobre la reparación integral transformadora para las mujeres sobrevivientes del conflicto armado interno, abordó los espacios de trabajo con mujeres que permitieron abrir reflexiones y debates cada vez más complejos y profundos respecto a las problemáticas específicas de las mujeres en el conflicto: las violencias que viven antes, durante y después de este, sus causas, sus efectos y los referentes nacionales e internacionales que establecen las reparaciones pertinentes, integrando cada experiencia y saber personal.

\footnotetext{
18 Véase VerdadAbierta.com. Delitos SEXuAles: PERsiste LA IMPUNIDAD. 16 de marzo de 2016. Disponible en http://www.verdadabierta.com/violencia-sexual/6208-delitos-sexuales-persistela-impunidad

19 Véase Corporación Sisma Mujer. LA REPARACIÓN INTEGRAL TRANSFORMADORA PARA LAS MUJERES SOBREVIVIENTES DEL CONFLICTO ARMADO COLOMBIANO: COMPRENSIÓN DEL DAÑO DIFERENCIAL Y PROPUESTA DE MEDIDAS DE REPARACIÓN. Corporación Sisma Mujer. (2014).
} 
De igual forma, la Corporación Sisma Mujer, en el informe presentado a varias organizaciones de mujeres y derechos humanos ${ }^{20}$, profundiza en las más de cinco décadas de duración de la violencia sociopolítica y del conflicto armado interno en Colombia, que han dejado miles de víctimas, entre ellas las mujeres víctimas de violencia sexual por los actores armados legales e ilegales, de quienes el país apenas comienza a ser consciente. Allí se presenta una descripción de "la realidad actual de persistencia de la violencia sexual contra las mujeres en el marco de la violencia sociopolítica y el conflicto armado interno en Colombia"21. El informe está acompañado de dos anexos: uno con casos documentados por organizaciones de mujeres y de derechos humanos y otro con relatos sobre violencias contra las mujeres tomados de diversas fuentes secundarias.

De este informe se concluyó que:

[...] Tal como se desprende de la información aquí aportada, el carácter sistemático y generalizado de la violencia sexual contra las mujeres en el marco de la violencia sociopolítica y del conflicto armado en el país es una realidad permanentemente monitoreada y denunciada por diversas organizaciones de mujeres y de derechos humanos, constatada por la Corte Constitucional colombiana y ratificada por los diversos informes provenientes de los sistemas internacionales de protección de los derechos humanos. Lo constatado por este informe da cuenta de la escasa voluntad política del Estado colombiano en el cumplimiento de su obligación de garantizar el acceso a la justicia para las mujeres víctimas de violencia sexual $[\ldots]^{22}$

De esta forma, se expone el estado de impunidad de la mayoría de los crímenes de violencia sexual, lo cual habilita la intervención de la Corte Penal Internacional en el país. Así lo indica un informe de Semana:

[...] impunidad en el 97\% de casos de violencia sexual por conflicto refleja el registro entre 2001 y 2009, tiempo en el cual 489.687 mujeres fueron víctimas directas de violencia sexual. Este dato representa que anualmente en promedio 54.410 mujeres fueron víc-

20 Véase Corporación Sisma Mujer. El Estado y LA violenCIA SEXUAL CONTRA LAS MUJERES EN EL MARCO DE LA VIOLENCIA sociopolítica en Colombia. Corporación Sisma Mujer. (2012).

21 Id. Pág. 2.

22 Id. Pág. 18. timas directas de algún tipo de violencia sexual, 149 diariamente y seis cada hora. La discriminación asociada a este hecho victimizante se ha convertido en uno de los principales obstáculos que enfrentan las víctimas de violencia sexual al momento de acceder a la justicia $[\ldots]^{23}$

Debido a lo anterior, para controlar o darle un debido proceso a este tipo de violaciones a los derechos humanos, se ha ajustado la normatividad colombiana con el trascurrir de los años, aunado a los avances en tratados internacionales y en recursos jurídicos. Es así como la Ley de Justicia y Paz-Ley 975 de 2005 nació como una forma de negociar la violencia política afianzada en el siglo xx, centrada en acuerdos para la desmovilización de los miembros de los grupos armados al margen de la ley. A pesar del gran número de demandas que tuvo la Ley de Justicia y $\mathrm{Paz}^{24}$, sus disposiciones fueron consideradas constitucionales, y la Corte estableció que uno de los parámetros fundamentales de esta ley son los destinados a proteger la participación de las víctimas en el proceso y su acceso a una reparación integral.

[...] Como lo señaló la Corte en la Sentencia C-370 de 2006, la alternatividad a que alude el artículo 3 de la Ley 975 de 2005 ha de entenderse establecida en el sentido de que "la colaboración con la justicia debe estar encaminada a lograr el goce efectivo de los derechos de las víctimas a la verdad, la justicia, la reparación y la no repetición", resalta la Corte. Desde esta perspectiva, es claro para la Corte que no pueden en manera alguna interpretarse las disposiciones en que se contiene la expresión acusada en un sentido que desconozca el cumplimiento por parte del Estado Colombiano de sus deberes y obligaciones frente a las víctimas respecto a sus derechos a la verdad, la justicia y la reparación, en armonía con las disposiciones constitucionales y los compromisos internacionales que de acuerdo con ellas este ha adquirido en estas materias $[\ldots]^{25}$

23 Véase Redacción Semana. IMPUNIDAD EN EL 97\% DE CASOs DE VIOLENCIA SEXUAL POR CONFlicto. Semana. 29 de mayo de 2016. Disponible en http://www.semana.com/nacion/articulo/ conflicto-impunidad-en-casos-de-violencia-sexual/475735

24 Para el caso, se pueden revisar, entre otras, las sentencias de la Corte Constitucional C-575 de 2006, C-531 de 2006, C-080 de 2006, C-370 de 2006 y C-1199 de 2008.

25 Véase Corte Constitucional de Colombia. Sentencia C-575/06. (M.P.: Álvaro Tafur Galvis; julio 25 de 2006). 
Como es sabido, la Ley de Justicia y Paz se centró en incentivar el desarme y la desmovilización de los miembros alzados en armas, especialmente de las AUC. Un aspecto fundamental de este proceso fue:

[...] asegurar el desmonte efectivo de las estructuras armadas que participaron del proceso de desmovilización, el procesamiento de los delitos para la obtención de verdad, justicia y reparación, y la progresiva reintegración de sus miembros a la sociedad a fin de lograr la no repetición de violaciones a los derechos humanos e infracciones graves al Derecho Internacional Humanitario-DIH $[\ldots]^{26}$

En este complicado esquema, la Corte Interamericana de Derechos Humanos (CIDH) reconoció una serie de objetivos en cumplimiento de los estándares internacionales en materia de verdad, justicia y reparación, siendo relevante para la investigación el referente a la "real y efectiva participación de las víctimas a lo largo de los procesos de investigación, juzgamiento y reparación" 27 .

Sin embargo, este último aspecto no se dio en cuanto a la reparación de las mujeres víctimas de violencia sexual; máxime si se tiene en cuenta que, en el marco de la Ley de Justicia y Paz, se generó una barrera para esta clase de delitos, debido a que esta ley fue creada para procesos de transición como un modelo de justicia alternativa, razón por la cual "no fueron consultadas las necesidades particulares de las mujeres víctimas del conflicto armado, perpetuando la discriminación histórica de las mujeres" ${ }^{28}$. También se puede señalar que la "Ley 975 de 2005 encarna desde su concepción una desproporción considerable entre las garantías a los victimarios en desmedro de las ofrecidas a las víctimas"29.

En consecuencia, Rosa Cadavid Rico expone que una forma de entender el conflicto armado colombiano es por medio de sus víctimas, y las mujeres, al igual que los niños, son las principales víctimas sobrevivientes de esta violencia. "Las violaciones ejercidas contra ellas a través del abuso sexual, el

26 CIDH, supra, nota 12, Pág. 136.

27 Id. Pág. 137.

28 Véase Comisión Nacional de Reparación y Reconciliación (CNRr). Tercer Panel: Justicia y reparación Para las mujeRES VÍ́CTIMAS DEL CONFLICTO ARMADO EN COLOMBIA. Seminario Justicia y Reparación para las Mujeres Víctimas del Conflicto Armado en Colombia. Universidad de los Andes. (Septiembre de 2010). Pág. 9.

29 CIDH, supra, nota 12, Pág. 9. desplazamiento forzado, el secuestro, la desaparición, la muerte y el control social son muestras fehacientes de su situación de vulnerabilidad y de la arraigada cultura machista que las convierte en armas de guerra y blancos de intimidación" 30 .

Así, el conflicto armado en Colombia se explora desde la perspectiva de la mujer a partir de ocho apartados, los cuales hacen referencia a la violencia de género, a la huida y el desarraigo, al cuerpo femenino como arma de guerra, a la militarización femenina, a la muerte, al silencio y la revictimización, a la sobrevivencia y a la mujer como conductora de paz. Se tiene entonces que:

[...] en el marco del conflicto colombiano, la mujer ha sido concebida como arma de guerra por los actores armados, por lo que es despojada de su dignidad y vida por medio de la violencia sexual, el secuestro, la tortura y el asesinato. Tal problemática tiene como base una arraigada cultura patriarcal en la que prima la dominación masculina; control que, en numerosos casos, es ejercido por medio de la violencia física $[\ldots]^{31}$

Debido a esto, debe ser una constante garantizar los principios de verdad, justicia, reparación y no repetición de la violencia ejercida contra la mujer en el contexto de la guerra en Colombia. La imposición de normas y conductas so pena de castigo en caso de incumplimiento ha sido un mecanismo permanente de represión en zonas donde el poder de los actores armados ilegales es mayor que el de las fuerzas del Estado.

Así, la mujer es una de las principales víctimas de la guerra en Colombia, y por ello, es vital su participación en el diseño de una agenda política para el posconflicto y la consecución de la paz. De ahí, la necesidad del enfoque diferencial de género que permite determinar el "rol del sujeto femenino en el contexto del conflicto armado interno colombiano y su condición de múltiple victimización"32. De tal forma, el enfoque diferencial de género va a ayudar

\footnotetext{
30 Véase Rosa Cadavid Rico. (2014). Mujer: blanco del conflicto armado en Colombia. Analecta Colombia 4. Julio-diciembre 2014. Pág. 303.

31 Id. Pág. 317.

32 Véase Claudia Lorena Sánchez Lucumí y Stephanie Oliveros Ortiz. La reparación integral a las víctimas mujeres: una aproximación a la aplicación del enfoque diferencial de género en el contexto del conflicto armado colombiano. UNIVERSITAs EsTUdiANTES 11. 2014. Págs. 163-185. Pág. 178.
} 
a construir el escenario que otorgue las medidas de reparación integral para las víctimas mujeres del conflicto armado en Colombia, dadas las falencias que al respecto tuvo la Ley 975 de 2005. La existencia de malas prácticas jurídicas y políticas por parte de los actores legales involucrados en la creación, reglamentación y aplicación de la Ley de Justicia y Paz fueron el derrotero para desarrollar un marco legal que apunte a lograr una verdadera transición, en el que se aporte a la transformación de la situación de opresión y subordinación que viven las mujeres.

Lo sucedido con la ley analizada condujo a proponer una nueva ley que no solo abarca lo contemplado en la Ley de Justicia y Paz, sino que además tiene mayor especificidad en cuanto al trato con las víctimas y la reparación, que se comprende en términos de justicia, reparación y perdón, lo que finalmente lleva a un examen entre los principios de reparación establecidos en la Ley 1448 de 2011 y la aplicación de un enfoque diferencial de género respecto a la reparación de los aspectos de la victimización femenina en el conflicto armado ${ }^{33}$.

La discriminación y la violencia contra la mujer son fenómenos "que hacen parte de las estructuras sociales que se han construido en el transcurso de la historia, por medio de tradiciones, la asignación de unos roles sexuados y la legitimación institucional de los mismos, en muchos casos" ${ }^{34}$. A su vez, también existen estándares internacionales particulares relacionados con los derechos de las mujeres y su situación en contextos bélicos, que son de obligatorio cumplimiento para Colombia vía bloque de constitucionalidad. Se tiene entonces que sobre los derechos humanos de las mujeres ${ }^{35}$, el DIH y los diferentes instrumentos de derecho internacional precisan su alcance y su contenido mucho más amplio, que debe irradiar la actividad del Estado respecto a la protección a la mujer.

\footnotetext{
33 Id. Pág. 163.

34 Id. Pág. 182.

35 Convención sobre la Eliminación de todas las Formas de Discriminación contra la Mujer, Ley 51 de 1981, Diario Oficial 35794; Convención Interamericana para Prevenir, Sancionar y Erradicar la Violencia contra la Mujer; Convención de Belém do Pará, Ley 248 de 1995, Diario Oficial 42171; Convención sobre los Derechos Políticos de la Mujer, Ley 35 de 1986, Diario Oficial 37345; Protocolo Facultativo de la Convención sobre la Eliminación de todas las Formas de Discriminación contra la Mujer, Ley 984 de 2005; Convención Interamericana sobre la Nacionalidad de la Mujer, Ley 77 de 1935, Diario Oficial 23075; Convención Interamericana sobre la Concesión de Derechos Políticos a la Mujer, Ley 8 de 1959, Diario Oficial 29927.
}

Así mismo, es necesario estudiar las leyes y los decretos en Colombia que respalden a la mujer víctima de violencia sexual en el marco del conflicto armado y hablar antes de sexo y de género, pues con este enfoque se trata de mirar la reparación de esta población: "El primero hace referencia al campo de la biología, mientras que el segundo hace referencia al campo de la cultura y la sociedad"36. Lo anterior se debe a que para entender toda la normatividad respecto a la guerra, se tiene que adentrar en el discurso de género:

[...] en el marco de una discusión no acabada sobre las causas y la historia de la discriminación de la mujer y de la forma como han sido construidos el orden y las relaciones humanas en el mundo, desde y en torno a quienes ejercen el poder $[\ldots]^{37}$

Con la Ley 1448 de 2011, se evidencia un cambio en el lenguaje, en la forma como fue escrita, dado que es más inclusivo con respecto a leyes previas sobre el desplazamiento y la violencia. Aquí ya se emplea la connotación de "víctima", en gran parte debido a los acuerdos que se han llevado a cabo con organismos internacionales; también contiene un enfoque diferencial, el cual refleja una realidad sexista que durante muchos años estuvo amparada por los gobiernos de turno, y ahora se diferencia con las reformas desde la justicia internacional que lleva a cambios que propenden a la igualdad.

Es así como en el marco de la Ley 1448 de 2011 o Ley de Víctimas y Restitución de Tierras se tiene un primer acercamiento a sus derechos en el Título II, que corresponde a "Derechos de las víctimas dentro de los procesos judiciales". Ya en lo pertinente a un proceso jurídico de violencia sexual en el marco del conflicto armado, el juez debe de apoyarse en el artículo 38 de la ley en exposición:

Artículo 38. Principios De la Prueba en CASOS DE VIOLENCIA SEXUAL. En los casos en que se investiguen delitos que involucren violencia sexual contra las víctimas, el Juez o Magistrado aplicará las siguientes reglas: 1 . El consentimiento no podrá

36 Véase Comisión Nacional de Género de la Rama Judicial. Justicia CONStitucional, MUJeres y GÉnero. Programa Integral Contra Violencias de Género. (2011). Pág. 8.

37 Véase Comisión Nacional de Género de la Rama Judicial. EL LENGUAJE: UN ELEMENTO ESTRATÉGICO EN LA CONSTRUCCIÓN DE LA IGUALdAD. Programa Integral Contra Violencias de Género. (2009). Pág. 7. 
inferirse de ninguna palabra o conducta de la víctima cuando la fuerza, la amenaza de la fuerza, la coacción o el aprovechamiento de un entorno coercitivo hayan disminuido su capacidad para dar un consentimiento voluntario y libre; 2 . El consentimiento no podrá inferirse de ninguna palabra o conducta de la víctima cuando esta sea incapaz de dar un consentimiento voluntario y libre; 3 . El consentimiento no podrá inferirse del silencio o de la falta de resistencia de la víctima a la supuesta violencia sexual; 4 . La credibilidad, la honorabilidad o la disponibilidad sexual de la víctima o de un testigo no podrán inferirse de la naturaleza sexual del comportamiento anterior o posterior de la víctima o de un testigo; 5 . El Juez o Magistrado no admitirá pruebas sobre el comportamiento sexual anterior o ulterior de la víctima o de un testigo.

La vinculación del enfoque de género requiere un adecuado conocimiento de la norma y, por consiguiente, de su interpretación, "siendo necesario la destrucción de los prejuicios que se albergan en torno al género y la orientación sexual y que dificultan una edificación social armónica" 38 . En ese caso, vale la pena hacer mención de la Ley 1257 de 2008, cuyo artículo 2 establece la definición de violencia contra la mujer:

[...] cualquier acción u omisión, que le cause muerte, daño o sufrimiento físico, sexual, psicológico, económico o patrimonial por su condición de mujer, así como las amenazas de tales actos, la coacción o la privación arbitraria de la libertad, bien sea que se presente en el ámbito público o en el privado [...]

Dicha definición se convirtió en el estandarte de la protección a la mujer en materia de violencia; sin embargo, en el componente de protección integral previsto por la Ley 1257 de 2008 "se ha tenido que enfrentar al incumplimiento generalizado por parte de las autoridades, comprometiendo y afectando ciertamente los derechos a la vida e integridad de las mujeres víctimas de violencias, entre otros" 39 .

Esto lleva a establecer, de facto, que el sistema de prevención y reparación de protección a la mujer

38 Véase Comisión Nacional de Género de la Rama Judicial, supra, nota 36, Pág. 27.

39 Véase Andrea Catalina León Amaya y Linda María Cabrera Cifuentes. Ley 1257. OCHO AÑos DE OBSTÁCUlOS EN LA PROTECCIÓN INTEGRAL PARA LAS MUJERES VÍCTIMAS DE VIOLENCIAS. Corporación Sisma Mujer. (2008). Pág. 76. dista mucho de la realidad y más aún si se tiene en cuenta que la sociedad colombiana es altamente patriarcal o "machista", y que "había imperado en el contexto colombiano, la violencia contra la mujer había sido considerada como un hecho normal, algo que la mujer debía de aceptar ya que la sumisión era su rol principal para el funcionamiento de una familia tradicional"40. La guerra toca a todos los habitantes de un territorio, pero el género femenino se encuentra atado a una historia y a una carga social y cultural que pone a las mujeres en una posición de vulnerabilidad manifiesta.

Entonces, a pesar del avance en la inclusión correspondiente al género y a la orientación sexual, queda por analizar los alcances de la Ley 1448 de 2011 respecto a los mecanismos de reparación de las víctimas de violencia sexual en el marco del conflicto armado, con énfasis en los requerimientos reales de las mujeres víctimas desde su condición.

El enfoque diferencial en las medidas de reparación integral ha sido un tema con poca profundización teórica. Pero ¿qué se entiende por reparación integral? Esta es vista como un derecho que se obtiene cuando ocurre una violación a los derechos humanos; entre estos derechos, la víctima puede llegar a solicitar medidas individuales de restitución, indemnización y rehabilitación. Hablando ya sobre una reparación colectiva, las medidas empleadas son dirigidas a restaurar, indemnizar o readaptar los derechos de las colectividades o comunidades afectadas directamente por las violaciones a los derechos humanos y al DIH.

La ley colombiana aún tiene un gran trabajo en materia de reparación para dar garantía de un proceso que, en la medida de lo posible, trate de ser dignificante y no de llegar a revictimizar o a ser agresor en el transcurso de los mecanismos reparadores.

\section{La situación de las mujeres víctimas de violencia sexual en la Inspección El Placer en el municipio Valle del Guamuez, en Putumayo - Estudio de caso}

La Alianza Departamental de Mujeres del Putumayo desarrolló un informe en homenaje a las víctimas del Putumayo y a las niñas Galárraga, dado que:

\footnotetext{
40 Véase Redacción El Tiempo. LAS DRAMáticas CIFRAS DE la violencia contra la mujer en Colombia. El Tiempo. 24 de noviembre de 2016. Disponible en http://www.eltiempo.com/vida/ salud/violencia-contra-la-mujer-en-colombia-42074
} 
[...] la situación de guerra del Putumayo, intensificada desde el año 2000 con el Plan Colombia y la lucha territorial de la guerrilla de las FARC y los grupos paramilitares, ha afectado especialmente a las mujeres, los niños, niñas y jóvenes. Las mujeres en el departamento del Putumayo, quienes representan la mitad de la población, han visto transformado su papel tradicional ante la guerra, el desplazamiento, el hambre y los impactos de las fumigaciones indiscriminadas. Desde el año 2003 diferentes organizaciones femeninas y lideresas se organizaron en la Alianza Departamental de Mujeres Tejedoras de Vida, y acompañadas por la Asociación Minga, han asumido un papel fundamental en la preservación del tejido social y productivo de la región, en la denuncia, la protección, la defensa de los derechos humanos y la visibilización de la situación de violencia contra las mujeres y las estructuras de poder que las someten y afectan. Alrededor de este trabajo han desarrollado dos investigaciones sobre la situación de las mujeres urbanas y rurales, indígenas, afros, campesinas y víctimas del conflicto (2007 y 2009). Su meta actual: empoderar a las múltiples organizaciones femeninas, lograr verdad y justicia frente a la impunidad de las violaciones contra las mujeres y su familia e incidir en cambios reales en la vida de las mujeres a través de políticas públicas basadas en sus necesidades y prioridades $[\ldots]^{41}$

El informe se elaboró con el objetivo de desarrollar una gran movilización de mujeres del suroccidente y dos eventos simbólicos y políticos que reivindiquen los derechos de las mujeres víctimas del Putumayo, teniendo como caso emblemático la desaparición de las cuatro niñas Galárraga y la lucha de su madre y de su hermana por encontrarlas.

Lo anterior es un abrebocas al estudio de caso que se centra en la Inspección El Placer, perteneciente al municipio Valle del Guamuez en Putumayo. Las historias de la inspección, el municipio y el departamento han estado enlazadas en la línea temporal por el conflicto armado, la guerrilla, los paramilitares y el narcotráfico.

[...] A este territorio, construido por colonos desde la década de los sesenta, llegó la bonanza de la coca y los habitantes vieron irrumpir e instalarse de manera

41 Véase Alianza Departamental de Mujeres del Putumayo. Homenaje a las niñas Galárraga. Tejedoras de Vida. (2010). Pág. 12. sucesiva a las mafias del narcotráfico, al Frente 48 de las FARC y al Bloque Sur Putumayo de las Auc. Cada uno de ellos impuso distintas reglas de juego tanto en la economía de la coca como en la vida cotidiana de los habitantes $[\ldots]^{42}$

A la Inspección El Placer la conforman diez veredas, además del casco urbano que lleva su nombre. El territorio fue colonizado en los años sesenta por campesinos nariñenses. Su característica más relevante ha sido tener grandes extensiones de cultivos de coca, además de ser zona de comercialización de bandas dedicadas al narcotráfico y territorio de las confrontaciones entre el Frente 48 de las FARC, la Fuerza Pública y grupos paramilitares.

La Inspección El Placer se encuentra ubicada a treinta minutos del municipio de La Hormiga, a dos horas de Puerto Asís y a dos horas en carro de la frontera con Ecuador. Por el occidente, está cerca de la frontera con Nariño; cerca pasa el río Guamuez, que separa esta inspección del municipio de Orito. Esta región ha tenido que soportar las reglas impuestas por cada uno de los actores del conflicto armado, los cuales pretendían regular el diario vivir de sus habitantes. Los agravios cometidos por las FARC y las AUC tuvieron manifestaciones e incidencias distintas, teniendo en cuenta también el género.

Las AUC, aunque promovieron la prostitución, inculcaron un límite entre lo decente y lo indecente, clasificando a las mujeres en estas dos categorías. Una mujer "decente" era ejemplo en su comunidad de esposa, madre e hija -desde la sumisión y "las buenas costumbres"-, y establecía sus actitudes y de quién era correcto enamorarse y de quién no. La mujer "indecente" era catalogada como prostituta y con frecuencia era castigada a los ojos de la comunidad. La prostitución era algo común en la inspección y las mujeres que la ejercían podían llegar a ser rechazadas, pero no por su oficio, sino por el hecho de llegar a contraer alguna enfermedad de transmisión sexual. Esa figura era empleada estratégicamente con un objetivo puntual:

[...] Según el excomandante Arnolfo Santamaría, alias 'Pipa', las prostitutas se convirtieron en un mal necesario, ya que por medio de ellas se mantenía más control sobre las acciones de sus hombres contra las mujeres locales, como violación o acoso sexual. Sin

42 María Clemencia Ramírez, supra, nota 4. 
embargo, esta política tuvo que enfrentarse al descontento de las mujeres tradicionales del pueblo, como la abuela Noemí, recordada como la cacica del pueblo $\mathrm{y}$ autoridad que respetaban los distintos actores ar$\operatorname{mados}[\ldots]^{43}$

Uno de los castigos enfocados hacia las mujeres catalogadas como "colaboradoras" o militantes de las FARC era el destierro; cualquier lazo de consanguinidad era castigado de esta manera, evitando así cualquier posible tráfico de información -claro está que el destierro iba acompañado de amenazas de muerte, señalamiento y a veces retenciones-. Otro castigo fueron las labores domésticas, que era aplicado a mujeres detenidas en los retenes y acusadas de llevar objetos que las vincularan con la guerrilla; "en este tipo de sanciones la estigmatización operó como excusa para retener mujeres y hacerse a mano de obra femenina que supliera los quehaceres diarios de los combatientes" 44 .

Otra de las sanciones aplicadas, y de mayor incidencia en la dignidad de la mujer, era proveer sexo a los armados, aun cuando tenían los prostíbulos para minimizar las violaciones sexuales; sin embargo, el castigo era aplicado a mujeres acusadas de ser guerrilleras o de ser pareja de miembros del grupo insurgente. De modo que la violación sexual es empleada como forma de intimidación, castigo y "purificación":

[...] la violación se sustentó en la idea de que quien sostenía relaciones sexuales con el adversario se contaminaba, volviéndose parte de él. De esa manera, el abuso sexual fue un mecanismo de sanción y "limpieza" que se desplegó de manera atroz sobre el cuerpo femenino. Allí, el pene de los victimarios se convirtió en arma y los revólveres se tornaron falos para castigar a la víctima $[\ldots]^{45}$

Las violaciones eran también ejecutadas con miras a ofender a los hombres, al pueblo, al colectivo. Se dañaba el cuerpo de la mujer para así obstruir una supuesta procreación y proliferación del "enemigo". En general, los castigos hacia las mujeres eran pretexto y subordinación de un género al servicio de las necesidades de un deformado "ser superior", que en este caso es el hombre, el hombre que porta armas y tiene el poder de atemorizar, castigar y violar.

43 María Clemencia Ramírez, supra, nota 4, Pág. 175.

44 Id. Pág. 165.

45 Id. Pág. 168
La guerra en Putumayo se intensificó en el año 2000, cuando empezó -en gran parte por el Plan Colombia- y se recrudeció la lucha territorial entre las FARC, los grupos paramilitares y la Fuerza Pública. Toda la población se vio dolorosamente afectada, especialmente las niñas y las mujeres. Ellas, que eran soporte de sus comunidades y arrastraban ya el peso de las violaciones domésticas, hicieron frente con profunda valentía a la guerra, el desplazamiento, el hambre y los impactos de las fumigaciones indiscriminadas.

Sin embargo, todo este coraje acumulado año tras año solo representa una parte de la memoria histórica de las mujeres víctimas de la violencia, en la cual el Estado les ha fallado en miles de oportunidades y de diferentes formas, con lo que se ha creado una deuda inmensurable con el pasar del tiempo.

Sumado a lo anterior, existe un amplio marco normativo tanto nacional como internacional. A nivel nacional se tiene la referenciada Ley 1257 de 2008 y a nivel internacional el marco es más amplio porque existen varias convenciones ${ }^{46}$, cuyo objetivo es blindar a las mujeres y salvaguardar su desarrollo físico, social, cultural y económico. Sin embargo, los sucesos relacionados con la violencia sexual no dejan de aparecer, en especial en estas zonas y a pesar de la existencia de la mentada normatividad, las fallas continúan, siendo evidentes los índices de violencia sexual.

\section{RESUlTADOS}

En el presente capítulo, se compilaron los principales hallazgos presentados en la investigación que reflejan el trabajo de campo realizado en la Inspección El Placer, jurisdicción del municipio Valle del Guamuez en Putumayo, con siete mujeres que tuvieron la gentileza de contestar las preguntas realizadas. Así, en lo referente a si había sido víctima de violencia sexual, siete contestaron que sí.

46 Convención sobre la Eliminación de todas las Formas de Discriminación contra la Mujer; Convención Interamericana para Prevenir, Sancionar y Erradicar la Violencia contra la Mujer; Convención de Belém do Pará; Convención sobre los Derechos Políticos de la Mujer; Protocolo Facultativo de la Convención sobre la Eliminación de todas las Formas de Discriminación contra la Mujer; Convención Interamericana sobre la Nacionalidad de la Mujer; Convención Interamericana sobre la Concesión de Derechos Políticos a la Mujer. 
En el marco del conflicto armado, las violaciones sexuales han sido una constante. Así lo señaló El Espectador en el 2012: El Placer, en el Bajo Putumayo, vivió una violencia que comenzó "el 7 de noviembre de 1999, cuando los paramilitares llegaron al pueblo. En ese momento, El Placer era controlado por el Frente 48 de las FARC, aunque ya las AUC se movían por la región"47. En ese momento, la violencia sexual se hizo presente, debido a que "fue un arma del día a día, y a las sospechosas las violaban, mutilaban sus genitales o las empalaban. A las prostitutas del pueblo las condenaron porque, decían, habían trabajado con guerrilleros y, por ello, estaban sucias" ${ }^{\text {"48. }}$.

Se puede ver cómo los paramilitares violentaban a las mujeres sin importar la edad; así se registra en el informe periodístico presentado por VerdadAbierta: "[...] una niña de 8 años fue violada en el municipio Valle del Guamuez en Putumayo, pero en el municipio no existe una ruta de atención. Los familiares prefirieron pasar al Ecuador para que atendieran a la niña, la niña no resistió y murió" ${ }^{\prime 4}$. Este caso no es sino uno entre miles, ya que de acuerdo con los datos de "Amnistía Internacional, del total de las víctimas más del $80 \%$ corresponde a niñas menores de 18 años, población vulnerable que exige más atención del gobierno y de las instituciones" ${ }^{\prime 50}$.

Lo anterior respalda lo expresado por las mujeres entrevistadas en la Inspección El Placer; así, el relato de las víctimas hace referencia al abuso desmedido al que fueron sometidas, como se puede observar en las declaraciones y es corroborado en el siguiente relato:

[...] Después empezaron uno por uno a penetrarme, me golpeaban la cara, arrancaron mi cabello, me metieron sus penes por la boca y en un momento empezaron a meterme sus pistolas en mi vagina. Luego me llenaron de arena y piedras en mi vagina y me dijeron que yo nunca me iba a olvidar de ellos $[\ldots]^{51}$

La Inspección El Placer fue un infierno debido a que los paramilitares abusaban de las mujeres, y las

\footnotetext{
47 Sebastián Jiménez Herrera, supra, nota 2.

$48 \quad$ Id.

49 VerdadAbierta.com. Nuevas amenazas para mujeres vícTIMAS DE VIOLENCIA SEXUAL. 22 de octubre de 2011. Disponible en http://www.verdadabierta.com/violencia-sexual/3609-nuevasamenazas-para-mujeres-victimas-de-violencia-sexual-en-el-conflicto

$50 \quad I d$.

51 Jiménez Herrera, supra, nota 47
}

mataban si hablaban alto o si caminaban rápido. 'A las embarazadas las obligaban a desnudarse para que demostraran que sus panzas no eran de mentiras y que bajo sus camisetas no guardaban armas para las Farc. Eran como caníbales, como demonios', indicó un sobreviviente de la época" ${ }^{\prime 2}$. En ese orden de ideas, se denota que aún siguen las violaciones sexuales y que a las mujeres se les utiliza como arma de guerra. Así lo declara la Corte Constitucional (Auto 092 del 2008) a través del periódico El Heraldo:

[...] La violencia sexual es una práctica habitual, extendida, sistemática e invisible en el contexto del conflicto armado colombiano, así como lo son la explotación y el abuso sexuales, dicta un auto de la Corte Constitucional emitido en 2008 que retrata una realidad silenciosa que se vive a diario en Colombia, la violencia de género como un arma de guerra $[\ldots]^{53}$

La Inspección El Placer ha sido un punto clave del conflicto, debido a que ha tenido que soportar las tres fuerzas del terrorismo colombiano: el narcotráfico, las FARC y las AUC, que se han caracterizado por violentar a la mujer en todas las formas posibles, siendo la violencia sexual la más denigrante y que sigue latente.

La siguiente pregunta se orientó a establecer la edad en que la víctima sufrió la violación. Las respuestas oscilan entre los 14 y los 35 años, siendo el rango de mayor frecuencia entre 18 y 25 años (tres respuestas), seguido de las mujeres entre 14 y 18 años (dos respuestas) y por último las mujeres entre 25 y 35 años (dos respuestas). Con respecto a las continuas violaciones a las que fueron sometidas las mujeres, se puede asegurar que quedaron plasmadas en sus memorias y nunca pudieron volver a ser las mismas, tal como narra una de las víctimas: “[...] los 'paras' le dijeron que eso le pasaba 'por guerrillera, por ser una prostituta cochina [...]'. Y agregó la mujer: '[...] Después de esa noche mi vida cambió mucho, yo como mujer quedé inservible [...] Durante meses yo no quise ver a nadie [...]"'.

Se pueden visualizar los múltiples abusos a mujeres menores de edad, quienes eran obligadas

\footnotetext{
52 Id.

53 Redacción El Heraldo. ViOLENCIA SEXUAL, EL CRIMEN SILENCioso Del Conflicto ARmado. El Heraldo. 6 de abril de 2015 Disponible en https://www.elheraldo.co/politica/violencia-sexual -el-crimen-silencioso-del-conflicto-armado-190276
} 
a hacer de acompañantes de los cabecillas de los paramilitares e incluso a convertirse en trabajadoras sexuales:

[...] Ser prostituta en un territorio cocalero, y que además se encuentra bajo el dominio paramilitar, implicó habitar muchos espacios que interferían con la vida cotidiana de la población civil. Estos espacios se dispersaron y aumentaron con la instalación de la base paramilitar. El puesto de fuente de soda se caracterizaba por ser una especie de cantina. Allí se vendía licor y se bailaba. Los clientes eran hombres civiles y armados de distintas edades atendidos por mujeres jóvenes. Muchas de ellas en su mayoría nariñenses o putumayenses, menores de edad, con bajo nivel de escolaridad y de origen económico precario $[\ldots]^{54}$

Las mujeres colombianas, en el marco del conflicto armado interno, han sido violentadas sin importar si son miembros de algún grupo armado ilegal o si pertenecen al amplio grupo de la población civil; como sea, en cualquiera de las dos situaciones han sido víctimas de violencia sexual.

"En medio de una cultura patriarcal y machista como la colombiana, las violencias sexuales en el marco del conflicto armado hacen parte del continuum de las violencias que las mujeres enfrentan día a día y cuya invisibilidad, justificación y naturalización" 55 constituyen los derroteros para la justicia colombiana dentro y fuera del país. Situación que ha llevado al Estado a ser denunciado ante la Corte Interamericana de Derechos Humanos.

Después, se cuestionó a las víctimas sobre cuál frente de los paramilitares las atacó. Como complemento, se preguntó también por el año en que se efectuó la violación, con lo que se estableció que los abusos sexuales tuvieron lugar entre el año 2000 y el 2007 a manos de los paramilitares. Las entrevistadas no hicieron mención del frente que las atacó y cuando se les preguntó si alguna había pertenecido a algún frente paramilitar, todas contestaron que no.

"En el marco del conflicto armado de Colombia, la mujer ha sido usada como arma de guerra, de intimidación, el cuerpo femenino pierde valor y se

54 María Clemencia Ramírez, supra, nota 4, Pág. 183.

55 Red Nacional de Mujeres, Ruta Pacífica de Mujeres, DeJusticia, et al. El Estado y la violencia sexual contra LAS MUJERES EN EL MARCO DE LA VIOLENCIA SOCIOPOLÍTICA EN Colombia. DeJusticia. Disponible en https://www.dejusticia.org/ wp-content/uploads/2017/04/fi_name_recurso_265.pdf. Pág. 7. convierte en mercancía sobre la que decide no la mujer misma, sino el enemigo" ${ }^{56}$. El uso de esta violencia, lejos de ser esporádico, ha prevalecido en el tiempo como práctica habitual del conflicto armado, la cual debería ser absolutamente reconocida por el Estado colombiano a fin de disminuir los índices de impunidad de este tipo de delitos, siendo temas aislados la investigación, los castigos y la reparación

$\mathrm{Si}$ bien es cierto que las entrevistadas fueron abusadas y maltratadas sexualmente por miembros de las AUC, también lo es que no formaban parte de ningún grupo paramilitar, ya que eran obligadas a servirles y a atenderlos en lo que ellos necesitaran y su permanencia con los integrantes del grupo armado ilegal era forzada; debido a esto, no solo fueron víctimas de violación, sino que también fueron objeto de destierro, amenazas de muerte, estigmatizaciones y retenciones y fueron obligadas a realizar labores domésticas; máxime cuando vivían en un zona cuya importante ubicación geográfica hizo que dichos integrantes tuvieran fuerte presencia en el periodo objeto de estudio de la presente investigación.

En cuanto a conocer si la víctima denunció la violación, se encontró que en la mayoría de los casos el miedo y el temor de recibir alguna represalia les impidieron hablar del tema, a lo cual de las siete víctimas encuestadas tres dijeron que sí y cuatro no la denunciaron.

En vista de tanta amenaza y corrupción, no se hicieron las respectivas denuncias de los abusos y violaciones a los que las sometieron; "el 82\% de las víctimas no lo denuncia. Decide callar. Como si el cuerpo luego del dolor también tuviera que acostumbrarse al silencio" ${ }^{\text {57 }}$. A esto se suma la falta de sanciones disciplinarias de la Procuraduría por tales hechos. La mayoría de las investigaciones permanecen congeladas: "Es claro que la Procuraduría no ha tomado con seriedad su deber de investigar y determinar posibles responsabilidades disciplinarias" 58 .

Respecto a la pregunta de ante qué entidad hizo la denuncia, se encontró que de las tres víctimas que denunciaron dos lo hicieron ante la Defensoría del

\footnotetext{
56 María Clemencia Ramírez, supra, nota 4, Pág. 86

57 Laura Marcela Hincapié. Violencia Sexual, Delito inviSible detrás del conflicto armado. El País. 17 de agosto de 2011. Disponible en http://www.elpais.com.co/judicial/violenciasexual-delito-invisible-detras-del-conflicto-armado.html

58 VerdadAbierta.com. DeLITOS SEXUALES: PERSISTE LA IMPUNIDAD. 16 de marzo de 2016. Disponible en http://www.verdadabierta. com/violencia-sexual/6208-delitos-sexuales-persiste-la-impunidad
} 
Pueblo y la otra lo hizo ante la Fiscalía de Justicia y Paz. Este hecho denota los bajos índices existentes en materia de denuncia y en sus respectivas judicializaciones.

A la pregunta de si ha formado parte del programa de reparación de víctimas en el marco de la Ley de Justicia y Paz, se pudo observar que la falta de conocimiento ha sido una de las principales causas para que las víctimas de abuso sexual no hayan recibido reparación ni apoyo de las entidades existentes. Además, "la Ley de Justicia y Paz no fue un mecanismo efectivo para que víctimas de las violencias sexuales perpetradas por los grupos paramilitares puedan acceder a sus derechos a la verdad, a la justicia y a la reparación" 59 .

Por tal razón, se puede afirmar que no existió una política de atención a las víctimas de violencia sexual que provea el restablecimiento integral de sus derechos, debido a que no existe la coordinación y articulación que permita proveer servicios de forma suficiente y completa. Aspecto que aún no ha sido superado por la Ley de Víctimas, "debido a que no se han logrado establecer unas garantías dentro del ámbito de la reparación, estas garantías se encuentran desarticuladas de los procesos judiciales y aún se encuentra en etapa de implementación"60.

Quizá, uno de los mayores avances en la materia ha sido el Decreto 1480 de 2014, por el cual se estableció el 25 de mayo como el día nacional por la dignidad de las mujeres víctimas de violencia sexual en el marco del conflicto armado interno, como una medida de reparación simbólica, debido a que "según las cifras de la Unidad para las Víctimas, en la actualidad ascienden a 19.684, de las cuales el $93 \%$ son mujeres"61.

En cuanto a saber si le han cumplido con la reparación, se puede evidenciar que todas las falencias que se presentan en el apoyo que se les debería dar a las víctimas de violencia sexual radican en la

59 Camila Hoyos y Mariana Medina. Represión de LA VIOLENCia SEXUAL EN COlOMbia y JUSTICIA INTERNACiONAL. INFORME DE OBSERVACIÓN DE JUICIO DE VIOLENCIA SEXUAL EN EL MARCO Del CONFlicto ARMado Colombiano. Corporación Humanas Colombia y Abogados sin Fronteras. (2013), Pág. 7.

60 Id.

61 Esperanza González. 25 DE MAYo: Violencia SEXUAL, LA LUCha POR El empoderamiento. Programa de las Naciones Unidas para el Desarrollo (PNUD). Disponible en http://www. co.undp.org/content/colombia/es/home/presscenter/articles/ 2017/05/25/25-de-mayo-violencia-sexual-la-lucha-por-el-empoderamiento-.html falta de conocimiento y en el temor a denunciar al ver que a veces los paramilitares están aliados con las diferentes autoridades.

De esta forma, ningún caso de violencia sexual debería parecer pequeño o insignificante, sino que tendría que contar con profesionales y funcionarios capaces de representar a las víctimas y lograr que se haga justicia. Las promesas incumplidas de la Ley 1448 de 2011 han creado frustración entre las víctimas. El establecimiento de los servicios de salud y especialmente del apoyo psicosocial ha sufrido graves demoras, las necesidades educativas de las víctimas o de sus hijos no han sido debidamente atendidas o las ayudas a la vivienda han sido insuficientes y tardías. "La falta de respuesta por parte de otras instituciones responsables de cuestiones esenciales para que la reparación sea realmente integral como la educación, la vivienda, la salud o la exención del servicio militar obligatorio han hecho que los esfuerzos" ${ }^{\prime 2} \mathrm{de}$ la Unidad para las Víctimas sean percibidos como débiles por las víctimas.

En los últimos años, el Estado colombiano ha decidido encaminarse radicalmente hacia un modelo de justicia transicional, con el fin de idear e implementar mecanismos excepcionales que atiendan de manera suficiente los derechos de la sociedad a la verdad, la justicia, la reparación integral y la garantías de no repetición para superar las consecuencias de violaciones masivas y sistemáticas a los derechos humanos y graves infracciones al DIH.

En materia de reparación, los obstáculos enfrentados por las víctimas comienzan desde la etapa de la denuncia. Las víctimas de violencia sexual siguen enfrentando condiciones inadecuadas para interponer debidamente sus denuncias ante las autoridades pertinentes. No se tiende a garantizar el derecho a la privacidad. Los procedimientos son sumamente formales, complicados y largos. Además, resultan muy costosos y conducen a las mujeres a desistir, lo que se agrava con la falta de información y asesoría. Otro factor que resulta determinante para que las víctimas no denuncien es la inefectividad de las medidas de protección, en particular las encaminadas a ofrecer protección a las víctimas de actos de violencia.

62 Centro Internacional para la Justicia Transicional. Estudio SObre la implementación del Programa de Reparación Individual en Colombia. Centro Internacional para la Justicia Transicional. (2015). Pág. 56 
En cuanto a la entrevista realizada a las autoridades municipales, una indica no saber del tema y dos dicen que sí. En lo concerniente a la reparación, contestaron con dilaciones, dando a entender que tienen poco conocimiento sobre el tema:

[...] Por tanto, en caso de que la normatividad transicional no genere impactos positivos en el goce efectivo de los derechos de las víctimas a la verdad, justicia, reparación y garantías de no repetición, la instancia rectora de la política criminal del Estado está llamada a promover los ajustes pertinentes a fin de materializar los derechos de las víctimas para quienes el ordenamiento jurídico internacional prevé derechos específicos en contextos de Justicia Transicional $[\ldots]^{63}$

Lo anterior es respuesta a lo planteado por la Corte Constitucional en Sentencia C-228 de 2002, que marcó el hito del proceso de reconocimiento de los derechos fundamentales de las víctimas en Colombia, cuando estableció que las víctimas en el proceso penal tendrían tres garantías: el derecho a la verdad, el derecho a la justicia y el derecho a que no haya impunidad. Resulta entonces preocupante que pasados quince años de este pronunciamiento jurisprudencial se continúe en un punto de estancamiento frente al tema de reparación, y peor aún, cuando se trata de la violencia sexual contra la mujer en el marco del conflicto armado interno.

\section{Conclusiones}

A partir de la investigación realizada, se deduce que en la Ley de Justicia y Paz no existió un reconocimiento a las víctimas de violencia sexual, razón por la cual no tuvo lugar la reparación para esta clase de delitos. Esto llevó a que la situación de las mujeres como víctimas en el marco del conflicto se dilatara más, haciendo que estos delitos continuaran en cierta forma invisibilizados, tal como lo muestra lo abordado en el artículo.

Con el trabajo de campo realizado, se concluye que la situación frente a las denuncias por violencia sexual y sus respectivas investigaciones no ha cambiado ni ha avanzado; por eso es amplia la necesidad

63 Corte Constitucional de Colombia. Auto 009/15. (M.P.: Luis Ernesto Vargas Silva; enero 27 de 2015). de que los casos de violencia sexual que adelante e investigue la Fiscalía General de la Nación, en conjunto con el Cuerpo Técnico de Investigación (сті) y con la Seccional de Investigación Judicial (Sijín), adscrita a la División de Investigación Judicial (Dijín) de la Policía Nacional, sean tramitados con seriedad y con estricto cumplimiento de los principios de igualdad, moralidad, eficacia, imparcialidad y publicidad sobre los cuales se fundamenta la función administrativa.

Así mismo, es necesario que, en virtud del principio de convencionalidad, estas autoridades soporten sus actuaciones con apego especial no solo a la normatividad nacional, sino también a la internacional, cuyos marcos normativos propenden a la protección de las víctimas de este flagelo; y que siguiendo esa línea, dichas autoridades tengan claro que la violencia sexual es un crimen de guerra y al adelantarse las investigaciones con prontitud, eficacia $y$ al judicializarse a sus perpetradores, la administración de justicia gane confianza en las víctimas. Con el presente argumento, se considera que las víctimas se animarán a denunciar estos actos y serán un referente para que otras lo hagan y no callen.

En ese orden de ideas, poco a poco se logrará que en materia de violencia sexual la pena cumpla con uno de sus fines que es la prevención general, la cual concentra su mensaje para que tanto los actores armados como la sociedad civil eviten la comisión de esta clase de delitos.

Bajo esta premisa, se encuentra que pese a existir un fuerte marco normativo, una sólida estructura de políticas públicas, un conjunto de entidades que generan la protección de la mujer en forma de movimientos sociales, es claro que en Colombia continúa existiendo una clara invisibilización de las víctimas de violencia sexual en el marco del conflicto armado, amparado por los operadores judiciales, que constituye un gran derrotero frente al deseo de proteger los derechos de las mujeres.

Debido a las problemáticas y falencias referenciadas, se observa que se ha incrementado en el país la violación masiva y sistemática de los derechos humanos, las infracciones a las normas del DIH y la presencia del Estado colombiano ante la CIDH, como una forma de llamar la atención frente a las fallas estructurales que tanto en materia de investigación y judicialización como de reparación ha tenido el país, sin importar lo establecido por la Ley 1448 de 2011-Ley de Víctimas y Restitución de Tierras en el marco de la justicia transicional. Entonces, continúa 
existiendo una clara necesidad de fortalecer las medidas tendientes a que las graves violaciones a los derechos de la mujer tengan una efectiva reparación y no se queden en reparación simbólica como lo dispone el Decreto 1480 de 2014.

Aunado a lo anterior, se debe formar y capacitar de manera permanente y constante a los funcionarios competentes de realizar las investigaciones, judicializaciones e intervenciones en pro de las mujeres víctimas de violencia sexual; y también se debe en materia de acceso a la salud garantizarles mayor atención psicológica, dado que para ellas no es fácil denunciar y superar lo sucedido, pues las secuelas que quedan en su ser interior las afectan tanto al punto de que a muchas se les dificulta formar una familia por el temor a los hombres, las estigmatizaciones, los delirios de persecución y demás, y las que lo han podido hacer por lo general adoptan conductas de sobreprotección con sus hijos, con la convicción de que ellos no pasen por las mismas situaciones por las que ellas han pasado.

Por ello, se deben encontrar los mecanismos que permitan atacar aquellas situaciones de violencia sexual, garantizando que este delito deje de ser invisible. Pero también se debe continuar el constante diálogo con las víctimas para que se atrevan a denunciar, para que conozcan cómo funciona el esquema de reparación; es decir que "se apropien" de lo sucedido y no se queden solo en el papel de víctima "mendigando" una solución, máxime cuando se trate de violaciones a los derechos humanos e infracciones al DIH.

En la actualidad, el Estado colombiano está apuntando y concentrando sus fuerzas y todo su actuar, dentro del escenario del posconflicto, a que estos casos no queden impunes y a que sus responsables sean judicializados en el marco de la Justicia Especial para la Paz y de su órgano de cierre el Tribunal para la Paz, donde cada caso sucedido en el escenario del conflicto armado interno y con ocasión de este sea tratado por el modelo de justicia transicional con la verificación de si reúnen las condiciones de verdad, reparación y garantías de no repetición que se estatuyan en el Sistema Integral de Verdad, Justicia, Reparación y no Repetición.

Lo anterior es con el fin de que las decisiones que se adopten otorguen plena seguridad jurídica a quienes participaron de manera directa o indirecta en la comisión de tales conductas y contribuyan a lograr la tan anhelada paz de "forma estable y duradera”. El objetivo es que de los resultados obtenidos y de la efectividad de esta justicia con participación de actores claves como las víctimas, la sociedad civil y las organizaciones defensoras de derechos humanos, se alcance la meta de cambiar la historia de violencia e injusticias acontecidas en el territorio colombiano. Todo esto implica que en un futuro inmediato el país se perfile como referente en el ámbito internacional para otros países que estén atravesando por escenarios de violencia similares y se pueda contribuir a la solución de sus problemáticas.

En síntesis, con la investigación realizada se logra establecer que, desde un punto de vista social, la violencia sexual hacia las mujeres es y será un tema inacabado que requiere día a día fortalecer la estructura normativa y funcional para prevenir esta clase de delitos hacia las mujeres y más aún en el marco del conflicto armado interno, del cual se desprenden una serie de situaciones que contribuyen a que el tema sea de total vigencia y requiera ser estudiado, con el fin de saber en qué está el país en la materia. Los casos de violencia sexual no pueden continuar siendo vistos a la ligera y las políticas públicas existentes deben continuar su proceso de consolidación en pro de fortalecer los derechos fundamentales y sociales de las mujeres, con actuaciones en derecho; en donde no deben existir posturas ambiguas que terminen en las altas Cortes por una mala interpretación del acervo probatorio o por una mala interpretación de la norma.

\section{REFERENCIAS}

Alianza Departamental de Mujeres del Putumayo. Homenaje a las niñas Galárraga. Tejedoras de Vida. (2010).

Andrea Catalina León Amaya y Linda María Cabrera Cifuentes. LEY 1257. OCHO AÑOS DE OBSTÁCULOS EN LA PROTECCIÓN INTEGRAL PARA LAS MUJERES VÍCTIMAS DE violenCiAs. Corporación Sisma Mujer. (2008).

Ángela Carrillo. Desplazamiento forzado y violencia sexual basada en género. Ed. Consejo Noruego para Refugiados. Buenaventura, Colombia: realidades bruTALES. (2014).

Camila Hoyos y Mariana Medina. Represión DE LA vioLENCIA SEXUAL EN COLOMBIA Y JUSTICIA INTERNACIONAL. INFORME DE OBSERVACIÓN DE JUICIO DE VIOLENCIA SEXUAL EN EL MARCO DEL CONFLICTO ARMADO COLOMBIANO. Corporación Humanas Colombia y Abogados sin Fronteras. (2013). 
Camila Medina. Conflicto armado y NARCotráfico. Caso: El Placer - Putumayo. Septiembre 27 de 2014. Disponible en http://centrodememoriahistorica.gov.co/descargas/CatedraBY/presentaciones/ Sesion-6/ConflictoArmadoNarcotrafico.pdf

Centro Internacional para la Justicia Transicional. Estudio SOBRE LA IMPLEMENTACión DEL PROgRama DE REPARACión INDividual EN Colombia. Centro Internacional para la Justicia Transicional. (2015).

Centro Nacional de Memoria Histórica (CNMH). Galerías FOTOGRÁfICAS SOBRE MEMORIA HISTÓRICA. Marzo 1 de 2004. Disponible en http://www.centrodememoriahistorica.gov.co/centro-audiovisual/galerias-fotograficas/el-placer-putumayo

Centro Nacional de Memoria Histórica (CNMH). ¡BASTA ya! Colombia: Memorias de GUerra y dignidad. CNMH. (2013).

Centro Nacional de Memoria Histórica (CNMH). Galería El Placer Putumayo. Fotografías de Jesús Abad Colorado y María Luisa Moreno. Marzo 1 de 2014. Disponible en http://www.centrodememoriahistorica.gov.co/de/informes/informes-2018/ el-placer-putumayo

Centro Nacional de Memoria Histórica (CNMH). EsPecial de memoria. Galería Bélica El Placer, PutuMAYO. Septiembre 23 de 2014. Disponible en https:// www.revistaarcadia.com/impresa/especial/articulo/ uno-galeria-belica-el-placer-putumayo/39004

Claudia Cecilia Ramírez. LEY 1257 DE 2008 SOBRE NO VIOLENCIAS CONTRA LAS MUJERES. HERRAMIENTAS PARA SU APLICACión E IMPLEMENTACión. Corporación Sisma Mujer. (2008).

Claudia Lorena Sánchez Lucumí y Stephanie Oliveros Ortiz. La reparación integral a las víctimas mujeres: una aproximación a la aplicación del enfoque diferencial de género en el contexto del conflicto armado colombiano. Universitas Estudiantes 11. 2014. Págs. 163-185.

Comisión Interamericana de Derechos Humanos (CIDH). VERDAD, JUSTICIA Y REPARACIÓN. CIDH. (2013).

Comisión Nacional de Género de la Rama Judicial. EL LENGUAJE: UN ELEMENTO ESTRATÉGICO EN LA CONSTRUCCIÓN DE LA IGUALDAD. Programa Integral Contra Violencias de Género. (2009).

Comisión Nacional de Género de la Rama Judicial. Justicia CONSTitucional, MUJERES y GÉnero. Programa Integral Contra Violencias de Género. (2011).
Comisión Nacional de Género de la Rama Judicial. CRITERIOS DE EQUIDAD PARA UNA ADMINISTRACIÓN DE JUSTICIA CON PERSPECTIVA DE GÉNERO. Consejo Superior de la Judicatura. (2012).

Comisión Nacional de Reparación y Reconciliación (CNRR). Tercer PANel: JUSTICIA Y REPARACIÓN PARA LAS MUJERES VÍCTIMAS DEL CONFLICTO ARMADO EN Colombia. Seminario Justicia y Reparación para las Mujeres Víctimas del Conflicto Armado en Colombia. Universidad de los Andes. (Septiembre de 2010).

Corporación Sisma Mujer. El Estado y la violencia SEXUAL CONTRA LAS MUJERES EN EL MARCO DE LA violencia sociopolítica en Colombia. Corporación Sisma Mujer. (2012).

Corporación Sisma Mujer. LA REPARACIÓN INTEGRAL TRANSFORMADORA PARA LAS MUJERES SOBREVIVIENTES DEL CONFLICTO ARMADO COLOMBIANO: COMPRENSIÓN DEL DAÑO DIFERENCIAL Y PROPUESTA DE MEDIDAS DE REPARACIÓN. Corporación Sisma Mujer. (2014).

Corte Constitucional de Colombia. Auto 009/15. (M.P.: Luis Ernesto Vargas Silva; enero 27 de 2015).

Corte Constitucional de Colombia. Auto 092/08. (м.P.: Manuel José Cepeda; abril 14 de 2008).

Corte Constitucional de Colombia. Sentencia C-228/02. (M.P.: Manuel José Cepeda Espinosa; abril 3 de 2002).

Corte Constitucional de Colombia. Sentencia C-575/06 (M.P.: Álvaro Tafur Galvis; julio 25 de 2006).

Decreto 1480 de 2014. Por el cual se declara el 25 de mayo como el día nacional por la dignidad de las mujeres víctimas de violencia sexual en el marco del conflicto armado interno. Agosto 5 de 2014. Do N. 49234.

Eduardo Pizarro Leongómez. UNA LECTURA MúltiPle Y PluRalista DE la historia. Comisión Histórica del Conflicto y sus Víctimas. (2015).

Esperanza González. 25 DE MAYo: Violencia SEXUAL, LA LUCHA POR El empoderamiento. Programa de las Naciones Unidas para el Desarrollo (PNUD). Disponible en http://www.co.undp.org/content/colombia/ es/home/presscenter/articles/2017/05/25/25-de-mayo-violencia-sexual-la-lucha-por-el-empoderamiento-.html

Heidi Tamayo Ortiz. Casos de violencia sexual serán emblemáticos Del CONFlicto. El Mundo. 18 de agosto de 2014. Disponible en http://www.elmundo. com/portal/noticias/derechos_humanos/casos_de_ violencia_sexual_seran_emblematicos_del_conflicto. php\#.WXQgK4g1_IU 
Laura Marcela Hincapié. Violencia SEXUAL, Delito INVISible detrás del Conflicto armado. El País. 17 de agosto de 2011. Disponible en http://www.elpais. com.co/judicial/violencia-sexual-delito-invisible-detras-del-conflicto-armado.html

Ley 1257 de 2008. Por la cual se dictan normas de sensibilización, prevención y sanción de formas de violencia y discriminación contra las mujeres, se reforman los Código Penal y Procedimiento Penal, la Ley 294 de 1996 y se dictan otras disposiciones. Diciembre 4 de 2008. Do N. ${ }^{\circ} 47193$.

Ley 1448 de 2011. Ley de Víctimas y Restitución de Tierras. Junio 10 de 2011. Do N. ${ }^{\circ} 48096$.

Manuel Muñiz. Estudio de CASO EN LA InvestigaCión Cualitativa. Disponible en http://www.psico.edu. uy/sites/default/files/cursos/1_estudios-de-caso-en-la -investigacion-cualitativa.pdf

María Clara Calle. Coca: un negocio familiar que marca a la mujer. Ed. Juan Diego Restrepo. MUJERES TRAS EL TELÓN DE LA GUERRA. Fundación Ideas para la paz. (2016).

María Clara Galvis. Situación en Colombia de la vioLENCIA SEXUAL CONTRA LAS MUJERES. Ediciones Ánthropos. (2009).

María Clemencia Ramírez. El Placer: Mujeres, coca y guerra en el Bajo Putumayo. Centro Nacional de Memoria Histórica. (2012).

Organización Internacional para las Migraciones (OIM). MuJERES Y CONFLICTO ARMADO. Unidad para la Atención y Reparación de las Víctimas. (2013).

Red Nacional de Mujeres, Ruta Pacífica de Mujeres, DeJusticia, et al. El Estado y LA VIOLENCIA SEXUAL CONTRA LAS MUJERES EN EL MARCO DE LA VIOLENCIA sociopolítica en Colombia. DeJusticia. Disponible en https://www.dejusticia.org/wp-content/uploads/2017/04/fi_name_recurso_265.pdf
Redacción El Heraldo. Violencia SEXUAL, EL CRIMEN SILENCIOSO DEL CONFLICTO ARMADO. El Heraldo. 6 de abril de 2015. Disponible en https://www.elheraldo.co/ politica/violencia-sexual-el-crimen-silencioso-delconflicto-armado-190276

Redacción El Tiempo. LAS DRAMÁtiCAS CIFRAS DE LA VIOlencia contra la mujer en Colombia. El Tiempo. 24 de noviembre de 2016. Disponible en http://www. eltiempo.com/vida/salud/violencia-contra-la-mujer-en-colombia-42074

Redacción Semana. IMPUNIDAD EN EL 97\% DE CASOS DE Violencia SEXUAL POR CONFlicto. Semana. 29 de mayo de 2016. Disponible en http://www.semana.com/ nacion/articulo/conflicto-impunidad-en-casos-deviolencia-sexual/475735

Robert E. Stake. Case studies. Ed. Yvonne S. Lincoln y Norman K. Denzin. Handbook of Qualitative ResearCH. Sage. (1994).

Roberto Hernández Sampieri, Carlos Fernández Collado y Pilar Baptista Lucio. Metodología de LA InvestigaCión. McGraw-Hill. (2010).

Rosa Cadavid Rico. (2014). Mujer: blanco del conflicto armado en Colombia. Analecta Colombia 4. Julio-diciembre 2014. Págs. 301-318.

Sebastián Jiménez Herrera. Cuando El Placer fue un INFIERNO. El Espectador. 28 de septiembre de 2012. Disponible en http://www.elespectador.com/noticias/ judicial/cuando-el-placer-fue-un-infierno-articulo378231

VerdadAbierta.com. Delitos SEXUALES: PERSISTE LA IMPUNIDAD. 16 de marzo de 2016. Disponible en http:// www.verdadabierta.com/violencia-sexual/6208-delitos-sexuales-persiste-la-impunidad

VerdadAbierta.com. Nuevas amenazas PARA MUJERES víCTIMAS DE VIOLENCIA SEXUAL. 22 de octubre de 2011. Disponible en http://www.verdadabierta.com/ violencia-sexual/3609-nuevas-amenazas-para-mujeres-victimas-de-violencia-sexual-en-el-conflicto 